\title{
Transcription Factor Nrf2 as a Potential Therapeutic Target for Prevention of Cytokine Storm in COVID-19 Patients
}

\author{
R. A. Zinovkin ${ }^{1,2,3, a *}$ and O. A. Grebenchikov ${ }^{4}$ \\ ${ }^{1}$ Belozersky Institute of Physico-Chemical Biology, Lomonosov Moscow State University, 119991 Moscow, Russia \\ ${ }^{2}$ Institute of Mitoengineering, Lomonosov Moscow State University, 119992 Moscow, Russia \\ ${ }^{3}$ Institute of Molecular Medicine, Sechenov First Moscow State Medical University (Sechenov University), \\ 119991 Moscow, Russia \\ ${ }^{4}$ Negovsky Research Institute of General Reanimatology, Russian Academy of Medical Sciences, 107031 Moscow, Russia \\ ${ }^{a}$ e-mail: roman.zinovkin@gmail.com
}

Received May 30, 2020

Revised June 4, 2020

Accepted June 4, 2020

\begin{abstract}
Nrf2 is a key transcription factor responsible for antioxidant defense in many tissues and cells, including alveolar epithelium, endothelium, and macrophages. Furthermore, Nrf2 functions as a transcriptional repressor that inhibits expression of the inflammatory cytokines in macrophages. Critically ill patients with COVID-19 infection often present signs of high oxidative stress and systemic inflammation - the leading causes of mortality. This article suggests rationale for the use of Nrf2 inducers to prevent development of an excessive inflammatory response in COVID-19 patients.
\end{abstract}

DOI: $10.1134 / \mathrm{S} 0006297920070111$

Keywords: Nrf2, SARS-CoV-2, COVID-19, cytokine storm, oxidative stress

\section{INTRODUCTION}

Pathogenesis of COVID-19 infection is a subject of active research. However, no effective therapy has yet been developed for this disease caused by the SARSCoV-2 coronavirus. Initially, SARS-CoV-2 infects upper respiratory tract epithelial cells. If the infection is limited to these cells, the disease usually manifests mild symptoms. Severe pneumonia can develop when the virus enters alveoli of the lungs and infects type II pneumocytes. The infection inhibits interferon response while upregulates expression of chemokines attracting immune cells (monocytes, B and T lymphocytes) [1]. Excessive extravasation of these cells from the vessels into the alveoli is considered the main cause of pathogenic changes in the lungs, leading to the development of respiratory failure and acute respiratory distress syndrome (ARDS) [2].

In severe cases of COVID-19 infection, the virus can enter bloodstream and infect endothelial and other target cells in kidneys, esophagus, bladder, ileum, heart tissues, and central nervous system. The endogenous "damage-

Abbreviations: ARDS, acute respiratory distress syndrome; ROS, reactive oxygen species.

* To whom correspondence should be addressed. associated molecular patterns, DAMPs" released from the dead cells additionally activate immune cells and support development of the cytokine storm. Thus, in severe forms of COVID-19 infection multiple organ failure associated with hyperactivation of the immune system is observed. Patients with COVID-19 infection in critical condition often have high systemic inflammatory parameters, including levels of $\mathrm{C}$-reactive protein and cytokines IL-6, TNF $\alpha$, IL-8, etc. [3-5].

Increased generation of reactive oxygen species (ROS) by immune cells and oxidative stress [6] inevitably accompanies the cytokine storm. Inflammatory cytokines and ROS act together, activating pulmonary epithelial and endothelial cells. This leads to disassembly of cell contacts, increased permeability, and influx of edematous fluid into alveoli resulting in an impaired gas exchange in the lungs. In addition, cytokine storm and oxidative stress lead to ROS-dependent apoptosis of endothelial cells [7], which contributes to the release of coagulation factors and clot formation [8].

Corticosteroids and inflammatory cascade inhibitors based on monoclonal antibodies are currently used for the treatment of the cytokine storm in COVID-19 infection: tocilizumab (anti IL-6), secukinumab (anti IL17A), canakinumab (anti IL-1 $\beta$ ), ruksolitinib phosphate 
(JAK kinase inhibitor), etc. [4]. Use of corticosteroids for treatment of COVID-19 infection showed noticeable constraints related primarily to the suppression of specific immunity and an increased risk of secondary bacterial pneumonia $[9,10]$. Limitations of the monoclonal antibody therapy include their narrowly targeted action at only one of the many inflammatory cytokines. Thus, it is extremely important to develop new approaches to prevent cytokine storm during the COVID-19 infection.

\section{DISCUSSION}

The transcription factor Nrf2 (Nuclear factor erythroid 2-related factor 2) is responsible for adaptation of cells under electrophilic or oxidative stresses. Under normal condition, Nrf2 is located in the cytoplasm bound to its inhibitor Keap1, which targets Nrf2 for ubiquitination and subsequent degradation. In the presence of electrophiles or ROS, the Keap1-Nrf2 complex dissociates and Nrf2 migrates to the nucleus, where it stimulates transcription of the target genes with antioxidant response element sequences in their promoters [11]. Nrf2 controls expression of the genes participating in antioxidant response, redox homeostasis, biogenesis of mitochondria, etc. Activation of these genes protects cells from inflammation [12]. Nrf2 stimulates expression of hemoxygenase (HO-1), which is responsible for degradation of the pro-inflammatory free heme and formation of the anti-inflammatory compounds - $\mathrm{CO}$ and bilirubin. Nrf2 also upregulates production of the antioxidant enzyme NAD(P)H: quinone oxidoreductase (NQO1), as well as of the key enzymes of glutathione biosynthesis, which functions as the main cellular antioxidant. Nrf2 knockout mice suffer from an uncontrolled inflammatory reaction involving activation of innate immune cells, increased production of cytokines, chemokines, and ROS. All these factors contribute to cell and tissue damage [13].

Nrf2 activation results in suppression of inflammation not only through the antioxidant response, but also through the Nrf2 transcriptional repressor activity. In human macrophages, Nrf2 inhibits expression of the inflammatory cytokines IL-1 $\beta$, IL-6, and TNF $\alpha$ [14]. It was shown in numerous animal inflammatory models that Nrf2 inducers decreased circulating levels of proinflammatory cytokines [12, 15-17]. Protective role of the Nrf2 activation in numerous inflammatory processes was also demonstrated for airway epithelium and vascular endothelium [18-22]. Dozens of clinical trials are currently underway to test the efficacy of Nrf2 inducers for prevention and treatment of inflammatory and respiratory diseases.

The main facts and observations justifying feasibility of the Nrf2 activation in treatment of COVID-19 infection are summarized below:
1. Excessive inflammation in COVID-19 infection is associated with high lethality [3]. Activation of Nrf2 reduces inflammatory response preventing expression of the inflammatory cytokines [14] and activation of the macrophage inflammasomes [23, 24]. Nrf2 inducers also reduce inflammatory reactions in patients with acute and chronic diseases [25].

2. ARDS is the main mortality factor in COVID-19 patients [26]. Activation of Nrf2 protects airway epithelium from disassembly of the intracellular tight junctions during inflammatory exposure and subsequent development of ARDS [27].

3. An impaired vascular permeability is a key event in the COVID-19 pathogenesis leading to endothelial dysfunction and thrombosis [28]. Induction of $\mathrm{Nrf} 2$ protects vascular endothelium from damage caused by the oxidative stress or inflammatory cytokines [29].

4. Severe cases of COVID-19 are accompanied by an increased oxidative stress [30]. There are some cases of successful treatment of COVID-19 with glutathione [31]. Key enzymes of glutathione biosynthesis are controlled by Nrf2 [32]. The decrease of Nrf2 activity promotes oxidative stress, and $\mathrm{Nrf} 2$ activation increases glutathione content in the body and restores redox balance in the organism [33].

5. Age is an important risk factor for severe COVID19 infection [34]. Nrf2 activity decreases with age [33].

6. Hyperglycemia is another risk factor in COVID19 infection [34]. Nrf2 activity is reduced in patients with hyperglycemia [35].

7. Mortality and severity of COVID-19 infection is higher in men compared to women [34]. Sexual differences in Nrf2 activity in humans are unknown, but female mice have higher Nrf2 activity compared to males [36].

So far, no attempts have been made to investigate $\mathrm{Nrf} 2$ inducers as the therapeutic drugs that reduce oxidative stress and inflammation in infections caused by SARS-CoV-2. This task can be solved by repurposing of the drugs or drug candidates that are able to activate Nrf2 response. A wide range of compounds can be used to activate $\mathrm{Nrf}$, including the following:

1. Sulforaphane is a plant-derived compound found in cruciferous plants such as broccoli and Brussels sprouts. The effect of sulforaphane on reducing circulatory inflammatory cytokines has been demonstrated in many animal models [37]. Currently, about 70 clinical trials with sulforaphane are conducted targeting chronic obstructive pulmonary disease, asthma, arthritis, cancer, and others. Sulforaphane is well tolerated orally in daily doses up to $200 \mu \mathrm{mol}$, reaching therapeutic plasma concentrations [38].

2. Dimethyl fumarate is a dimethyl ester of fumaric acid. In the USA it has been approved by the FDA for treatment of recurrent multiple sclerosis (trade name Tecfidera), and in Germany for psoriasis (trade name Fumaderm). Interestingly, dimethyl fumarate reduces 
inflammatory reactions in both Nrf2-dependent [39] and Nrf2-independent ways [40, 41].

3. Sodium thiosulfate is a drug used intravenously and orally. It is a safe substance used to treat various intoxications. Sodium thiosulfate is a hydrogen sulfide $\left(\mathrm{H}_{2} \mathrm{~S}\right)$ donor, which is a Nrf2 inducer. Hydrogen sulfide maintains redox balance of the cells and has an antiinflammatory property [42]. The compounds releasing $\mathrm{H}_{2} \mathrm{~S}$ have anti-inflammatory and antiviral activities against a wide range of pathogenic viruses [43]. A review paper has recently been published justifying the use of inhaled form of sodium thiosulphate for patients with COVID-19 infection [44].

4. Epigallocatechin 3-gallate is a polyphenol found in green tea. This non-toxic compound displays an antiinflammatory activity both in vitro and in vivo [45]. In addition, epigallocatechin 3-gallate is an inhibitor of furin - a protease that processes SARS-CoV-2 S protein and facilitates virus penetration into the cell [46-48].

5. Resveratrol is a plant polyphenol. Resveratrol activates Nrf2 by decreasing the expression of its negative regulator KEAP1 and activates SIRT1 deacetylase [49]. Oral administration of resveratrol leads to the decrease in the levels of inflammatory cytokines (IL-1 $\beta$ and TNF) and activation of the expression of $\mathrm{Nrf} 2$ target genes (NQO1 and glutathione S-transferase) [50]. Resveratrol enhances synthesis of endogenous glutathione and protects alveolar epithelial cells from oxidative stress [51].

These drugs are mainly used to treat chronic rather than acute inflammatory conditions. Therapeutic efficacy of these Nrf2 inducers is unknown for the cytokine storm and ARDS. Potentially, Nrf2 inducers can be used to prevent cytokine storm or during its manifestation in combination with already used anti-inflammatory drugs.

For most of the proposed drugs toxicity and bioavailability are already known, which allows for a quick start of the relevant clinical trials. To reduce oxidative stress and inflammation in COVID-19 infection, it seems reasonable to use $\mathrm{Nrf} 2$ inducers together with glutathione biosynthesis precursors, e.g., $\mathrm{N}$-acetylcysteine. This therapy can be used to reduce damage to cells and tissues, to prevent respiratory failure, and ARDS.

Funding. This work received no financial support.

Acknowledgements. The authors are grateful to A. S. Prikhodko for critical discussions.

Ethics declarations. The authors declare no conflict of interest in financial or any other sphere. This article does not contain any studies with human participants or animals performed by any of the authors.

\section{REFERENCES}

1. Blanco-Melo, D., Nilsson-Payant, B. E., Liu, W.-C., Uhl, S., Hoagland, D., Møller, R., Jordan, T. X., Oishi, K.,
Panis, M., Sachs, D., Wang, T. T., Schwartz, R. E., Lim, J. K., Albrecht, R. A., and tenOever, B. R. (2020) Imbalanced host response to SARS-CoV-2 drives development of COVID-19, Cell, 181, 1036-1045, doi: 10.1016/j.cell.2020. 04.026

2. Ackermann, M., Verleden, S. E., Kuehnel, M., Haverich, A., Welte, T., Laenger, F., Vanstapel, A., Werlein, C., Stark, H., Tzankov, A., Li, W. W., Li, V. W., Mentzer, S. J., and Jonigk, D. (2020) Pulmonary vascular endothelialitis, thrombosis, and angiogenesis in Covid-19, N. Engl. J. Med., doi: 10.1056/NEJMoa2015432.

3. Mehta, P., McAuley, D. F., Brown, M., Sanchez, E., Tattersall, R. S., Manson, J. J., and HLH Across Speciality Collaboration (2020) COVID-19: consider cytokine storm syndromes and immunosuppression, Lancet, 395, 10331034, doi: 10.1016/S0140-6736(20)30628-0.

4. Zhang, W., Zhao, Y., Zhang, F., Wang, Q., Li, T., Liu, Z., Wang, J., Qin, Y., Zhang, X., Yan, X., Zeng, X., and Zhang, S. (2020) The use of anti-inflammatory drugs in the treatment of people with severe coronavirus disease 2019 (COVID-19): the perspectives of clinical immunologists from China, Clin. Immunol., 214, 108393, doi: 10.1016/ j.clim.2020.108393.

5. Chen, G., Wu, D., Guo, W., Cao, Y., Huang, D., Wang, H., Wang, T., Zhang, X., Chen, H., Yu, H., Zhang, X., Zhang, M., Wu, S., Song, J., Chen, T., Han, M., Li, S., Luo, X., Zhao, J., and Ning, Q. (2020) Clinical and immunological features of severe and moderate coronavirus disease 2019, $J$. Clin. Invest., 130, 2620-2629, doi: 10.1172/JCI137244.

6. Schieber, M., and Chandel, N. S. (2014) ROS function in redox signaling and oxidative stress, Curr. Biol., 24, R453R462, doi: 10.1016/j.cub.2014.03.034.

7. Winn, R. K., and Harlan, J. M. (2005) The role of endothelial cell apoptosis in inflammatory and immune diseases, $J$. Thromb. Haemost., 3, 1815-1824, doi: 10.1111/j.15387836.2005.01378.x.

8. Klok, F. A., Kruip, M. J. H. A., van der Meer, N. J. M., Arbous, M. S., Gommers, D. A. M. P. J., Kant, K. M., Kaptein, F. H. J., van Paassen, J., Stals, M. A. M., Huisman, M. V., and Endeman, H. (2020) Incidence of thrombotic complications in critically ill ICU patients with COVID-19, Thromb. Res., 191, 145-147, doi: 10.1016/ j.thromres.2020.04.013.

9. Chen, N., Zhou, M., Dong, X., Qu, J., Gong, F., Han, Y., Qiu, H., Wang, J., Liu, Y., Wei, Y., Xia, J., Yu, T., Zhang, X., and Zhang, L. (2020) Epidemiological and clinical characteristics of 99 cases of 2019 novel coronavirus pneumonia in Wuhan, China: a descriptive study, Lancet, 395, 507-513, doi: 10.1016/S0140-6736(20)30211-7.

10. Zha, L., Li, S., Pan, L., Tefsen, B., Li, Y., French, N., Liyun Chen, L., Gang Yang, G., and Villanueva, E. V. (2020) Corticosteroid treatment of patients with coronavirus disease 2019 (COVID-19), Med. J. Aust., 212, 416420, doi: $10.5694 / \mathrm{mja} 2.50577$.

11. Motohashi, H., and Yamamoto, M. (2004) Nrf2-Keap1 defines a physiologically important stress response mechanism, Trends. Mol. Med., 10, 549-557, doi: 10.1016/ j.molmed.2004.09.003.

12. Ahmed, S. M. U., Luo, L., Namani, A., Wang, X. J., and Tang, X. (2017) Nrf2 signaling pathway: pivotal roles in inflammation, Biochim. Biophys. Acta Mol. Basis Dis., 1863, 585-597, doi: 10.1016/j.bbadis.2016.11.005. 
13. Kensler, T. W., Wakabayashi, N., and Biswal, S. (2007) Cell survival responses to environmental stresses via the Keap1Nrf2-ARE pathway, Annu. Rev. Pharmacol. Toxicol., 47, 89116, doi: 10.1146/annurev.pharmtox.46.120604.141046.

14. Kobayashi, E. H., Suzuki, T., Funayama, R., Nagashima, T., Hayashi, M., Sekine, H., Tanaka, N., Moriguchi, T., Motohashi, H., Nakayama, K., and Yamamoto, M. (2016) Nrf2 suppresses macrophage inflammatory response by blocking proinflammatory cytokine transcription, Nat. Commun., 7, 11624, doi: 10.1038/ncomms11624.

15. Thimmulappa, R. K., Scollick, C., Traore, K., Yates, M., Trush, M. A., Liby, K. T., Sporn, M. B., Yamamoto, M., Kensler, T. W., and Biswal, S. (2006) Nrf2-dependent protection from LPS induced inflammatory response and mortality by CDDO-imidazolide, Biochem. Biophys. Res. Commun., 351, 883-889, doi: 10.1016/j.bbrc.2006.10.102.

16. Lin, W., Wu, R. T., Wu, T., Khor, T.-O., Wang, H., and Kong, A.-N. (2008) Sulforaphane suppressed LPS-induced inflammation in mouse peritoneal macrophages through Nrf2 dependent pathway, Biochem. Pharmacol., 76, 967973, doi: 10.1016/j.bcp.2008.07.036.

17. Motterlini, R., Nikam, A., Manin, S., Ollivier, A., Wilson, J. L., Djouadi, S., Muchova, L., Martens, T., Rivard, M., and Foresti, R. (2019) HYCO-3, a dual CO-releaser/Nrf2 activator, reduces tissue inflammation in mice challenged with lipopolysaccharide, Redox Biol., 20, 334-348, doi: 10.1016/j.redox.2018.10.020.

18. Kosmider, B., Messier, E. M., Janssen, W. J., Nahreini, P., Wang, J., Hartshorn, K. L., and Mason, R. J. (2012) Nrf2 protects human alveolar epithelial cells against injury induced by influenza A virus, Respir. Res., 13, 43, doi: 10.1186/1465-9921-13-43.

19. Chan, K., and Kan, Y. W. (1999) Nrf2 is essential for protection against acute pulmonary injury in mice, Proc. Natl. Acad. Sci. USA, 96, 12731-12736, doi: 10.1073/pnas.96.22. 12731.

20. Boutten, A., Goven, D., Artaud-Macari, E., Boczkowski, J., and Bonay, M. (2011) NRF2 targeting: a promising therapeutic strategy in chronic obstructive pulmonary disease, Trends Mol. Med., 17, 363-371, doi: 10.1016/j.molmed. 2011.02.006.

21. Zakkar, M., Van der Heiden, K., Luong, L. A., Chaudhury, H., Cuhlmann, S., Hamdulay, S. S., Krams, R., Edirisinghe, I., Rahman, I., Carlsen, H., Haskard, D. O., Mason, J. C., and Evans, P. C. (2009) Activation of Nrf2 in endothelial cells protects arteries from exhibiting a proinflammatory state, Arterioscler. Thromb. Vasc. Biol., 29, 1851-1857, doi: 10.1161/ATVBAHA.109.193375.

22. Chen, X.-L., Dodd, G., Thomas, S., Zhang, X., Wasserman, M. A., Rovin, B. H., and Kunsch, C. (2006) Activation of Nrf2/ARE pathway protects endothelial cells from oxidant injury and inhibits inflammatory gene expression, Am. J. Physiol. Heart. Circ. Physiol., 290, H1862H1870, doi: 10.1152/ajpheart.00651.2005.

23. Jhang, J.-J., and Yen, G.-C. (2017) The role of Nrf2 in NLRP3 inflammasome activation, Cell. Mol. Immunol., 14, 1011-1012, doi: 10.1038/cmi.2017.114.

24. Zhao, C., Gillette, D. D., Li, X., Zhang, Z., and Wen, H. (2014) Nuclear factor E2-related factor-2 (Nrf2) is required for NLRP3 and AIM2 inflammasome activation, J. Biol. Chem., 289, 17020-17029, doi: 10.1074/jbc.M114. 563114.
25. Robledinos-Antón, N., Fernández-Ginés, R., Manda, G., and Cuadrado, A. (2019) Activators and inhibitors of NRF2: a review of their potential for clinical development, Oxid. Med. Cell. Longev., 2019, 9372182, doi: 10.1155/ 2019/9372182.

26. Wu, C., Chen, X., Cai, Y., Xia, J., 'an Zhou, X., Xu, S., Huang, H., Zhang, L., Zhou, X., Du, C., Zhang, Y., Song, J., Wang, S., Chao, Y., Yang, Z., Xu, J., Zhou, X., Chen, D., Xiong, W., Xu, L., Zhou, F., Jiang, J., Bai, C., Zheng, J., and Song, Y. (2020) Risk factors associated with acute respiratory distress syndrome and death in patients with coronavirus disease 2019 pneumonia in Wuhan, China, JAMA Intern. Med., doi: 10.1001/jamainternmed.2020. 0994.

27. Mehla, K., Balwani, S., Agrawal, A., and Ghosh, B. (2013) Ethyl gallate attenuates acute lung injury through Nrf2 signaling, Biochimie, 95, 2404-2414, doi: 10.1016/j.biochi. 2013.08.030.

28. Sardu, C., Gambardella, J., Morelli, M. B., Wang, X., Marfella, R., and Santulli, G. (2020) Is COVID-19 an endothelial disease? Clinical and basic evidence, J. Clin. Med., 9, E1417, doi: 10.3390/jcm9051417.

29. Chapple, S. J., Siow, R. C. M., and Mann, G. E. (2012) Crosstalk between Nrf2 and the proteasome: therapeutic potential of $\mathrm{Nrf} 2$ inducers in vascular disease and aging, Int. J. Biochem. Cell. Biol., 44, 1315-1320, doi: 10.1016/j.biocel.2012.04.021.

30. Buinitskaya, Y., Gurinovich, R., Wlodaver, C. G., and Kastsiuchenka, S. (2020) Highlights of COVID-19 pathogenesis. Insights into oxidative damage, doi: 10.6084/ m9.figshare.12121575.v9.

31. Horowitz, R. I., Freeman, P. R., and Bruzzese, J. (2020) Efficacy of glutathione therapy in relieving dyspnea associated with COVID-19 pneumonia: a report of 2 cases, Respir. Med. Case Rep., 101063, doi: 10.1016/j.rmcr. 2020.101063.

32. Li, N., Alam, J., Venkatesan, M. I., Eiguren-Fernandez, A., Schmitz, D., Di Stefano, E. Slaughter, N., Killeen, E., Wang, X., Huang, A., Wang, M., Miguel, A. H., Cho, A., Sioutas, C., and Nel, A. E. (2004) Nrf2 is a key transcription factor that regulates antioxidant defense in macrophages and epithelial cells: protecting against the proinflammatory and oxidizing effects of diesel exhaust chemicals, J. Immunol., 173, 3467-3481, doi: 10.4049/ jimmunol.173.5.3467.

33. Zhang, H., Davies, K. J. A., and Forman, H. J. (2015) Oxidative stress response and $\mathrm{Nrf} 2$ signaling in aging, Free Radic. Biol. Med., 88, 314-336, doi: 10.1016/j.freeradbiomed. 2015.05.036.

34. Richardson, S., Hirsch, J. S., Narasimhan, M., Crawford, J. M., McGinn, T., Davidson, K. W., and the Northwell COVID-19 Research Consortium (2020) Presenting characteristics, comorbidities, and outcomes among 5700 patients hospitalized with COVID-19 in the New York City area, JAMA, 323, 2052-2059, doi: 10.1001/jama.2020.6775.

35. Uruno, A., Furusawa, Y., Yagishita, Y., Fukutomi, T., Muramatsu, H., Negishi, T., Sugawara, A., Kensler, T. W., and Yamamoto, M. (2013) The Keap1-Nrf2 system prevents onset of diabetes mellitus, Mol. Cell. Biol., 33, 29963010, doi: 10.1128/MCB.00225-13.

36. Rooney, J., Oshida, K., Vasani, N., Vallanat, B., Ryan, N., Chorley, B. N., Wang, X., Bell, D. A., Wu, K. C., Aleksunes, 
L. M., Klaassen, C. D., Kensler, T. W., and Corton, J. C. (2018) Activation of Nrf2 in the liver is associated with stress resistance mediated by suppression of the growth hormone-regulated STAT5b transcription factor, PLoS One, 13, e0200004, doi: 10.1371/journal.pone.0200004.

37. Innamorato, N. G., Rojo, A. I., García-Yagüe, A. J., Yamamoto, M., de Ceballos, M. L., and Cuadrado, A. (2008) The transcription factor Nrf2 is a therapeutic target against brain inflammation, J. Immunol., 181, 680-689, doi: 10.4049/jimmunol.181.1.680.

38. Tahata, S., Singh, S. V., Lin, Y., Hahm, E.-R., Beumer, J. H., Christner, S. M., Rao, U. N., Sander, C., Tarhini, A. A., Tawbi, H., Ferris, L. K., Wilson, M., Rose, A., Dietz, C. M., Hughes, E. K., Fahey, J. W., Leachman, S. A., Cassidy, P. B., Butterfield, L. H., Zarour, H. M., and Kirkwood, J. M. (2018) Evaluation of biodistribution of sulforaphane after administration of oral broccoli sprout extract in melanoma patients with multiple atypical nevi, Cancer Prev. Res., 11, 429-438, doi: 10.1158/1940-6207.CAPR-17-0268.

39. Lin, S. X., Lisi, L., Dello Russo, C., Polak, P. E., Sharp, A., Weinberg, G., Kalinin, S., and Feinstein, D. L. (2011) The anti-inflammatory effects of dimethyl fumarate in astrocytes involve glutathione and haem oxygenase-1, $A S N$ Neuro, 3, doi: 10.1042/AN20100033.

40. Schulze-Topphoff, U., Varrin-Doyer, M., Pekarek, K., Spencer, C. M., Shetty, A., Sagan, S. A. Cree, B. A. C., Sobel, R. A., Wipke, B. T., Steinman, L., Scannevin, R. H., and Zamvi, S. S. (2016) Dimethyl fumarate treatment induces adaptive and innate immune modulation independent of Nrf2, Proc. Natl. Acad. Sci. USA, 113, 47774782, doi: 10.1073/pnas.1603907113.

41. Kornberg, M. D., Bhargava, P., Kim, P. M., Putluri, V., Snowman, A. M., Putluri, N., Snowman, A. M., Putluri, N., Calabresi, P., and Snyder, S. H. (2018) Dimethyl fumarate targets GAPDH and aerobic glycolysis to modulate immunity, Science, 360, 449-453, doi: 10.1126/science.aan4665.

42. Corsello, T., Komaravelli, N., and Casola, A. (2018) Role of hydrogen sulfide in NRF2- and sirtuin-dependent maintenance of cellular redox balance, Antioxidants (Basel), 7, doi: 10.3390/antiox7100129.

43. Bazhanov, N., Escaffre, O., Freiberg, A. N., Garofalo, R. P., and Casola, A. (2017) Broad-range antiviral activity of hydrogen sulfide against highly pathogenic RNA viruses, Sci. Rep., 7, 41029, doi: 10.1038/srep41029.

44. Evgen'ev, M. B., and Frenkel, A. (2020) Possible application of H2S-producing compounds in therapy of coronavirus (COVID-19) infection and pneumonia, Cell Stress Chaperones, doi: 10.1007/s12192-020-01120-1.

45. Ohishi, T., Goto, S., Monira, P., Isemura, M., and Nakamura, Y. (2016) Anti-inflammatory action of green tea, Antiinflamm. Antiallergy Agents Med. Chem., 15, 74-90, doi: 10.2174/1871523015666160915154443.

46. Zhu, J., Van de Ven, W. J. M., Verbiest, T., Koeckelberghs, G., Chen, C., Cui, Y., and Vermorken, A. J. M. (2013) Polyphenols can inhibit furin in vitro as a result of the reactivity of their auto-oxidation products to proteins, Curr. Med. Chem., 20, 840-850, doi: 10.2174/0929867311320060009.

47. Shang, J., Wan, Y., Luo, C., Ye, G., Geng, Q., Auerbach, A., and Li, F. (2020) Cell entry mechanisms of SARS-CoV2, Proc. Natl. Acad. Sci. USA, 117, 11727-11734, doi: 10.1073/pnas.2003138117.

48. Coutard, B., Valle, C., de Lamballerie, X., Canard, B., Seidah, N. G., and Decroly, E. (2020) The spike glycoprotein of the new coronavirus 2019-nCoV contains a furinlike cleavage site absent in CoV of the same clade, Antiviral Res., 176, 104742, doi: 10.1016/j.antiviral.2020.104742.

49. Ungvari, Z., Bagi, Z., Feher, A., Recchia, F. A., Sonntag, W. E., Pearson, K., de Cabo, R., and Csiszar, A. (2010) Resveratrol confers endothelial protection via activation of the antioxidant transcription factor Nrf2, Am. J. Physiol. Heart Circ. Physiol., 299, H18-H24, doi: 10.1152/ajpheart. 00260.2010 .

50. Ghanim, H., Sia, C. L., Korzeniewski, K., Lohano, T., Abuaysheh, S., Marumganti, A., Chaudhuri, A., and Dandona, P. (2011) A resveratrol and polyphenol preparation suppresses oxidative and inflammatory stress response to a high-fat, high-carbohydrate meal, J. Clin. Endocrinol. Metab., 96, 1409-1414, doi: 10.1210/jc.2010-1812.

51. Kode, A., Rajendrasozhan, S., Caito, S., Yang, S.-R., Megson, I. L., and Rahman, I. (2008) Resveratrol induces glutathione synthesis by activation of Nrf2 and protects against cigarette smoke-mediated oxidative stress in human lung epithelial cells, Am. J. Physiol. Lung Cell. Mol. Physiol., 294, L478-L488, doi: 10.1152/ajplung.00361.2007. 